\title{
Evaluation of Cerebral Blood Flow in Arteriovenous Malformations by the Xenon 133 Inhalation Method
}

\author{
DEVIDAS MENON and BRYCE WEIR
}

SUMMARY: Fifteen regional cerebral blood flow studies ( $C B F$ ) were conducted on 14 patients with arteriovenous malformations $(A V M)$. Only one patient was studied at the time of a hemorrhage. None of the patients were operated upon. All patients had angiographically demonstrated lesions. All the $C r$ scans performed demonstrated the lesions. $r C B F$ was increased in the involved hemisphere compared to the non-involved hemisphere and the difference was greater when the malformations were superficial. There was a higher incidence of high flow regions in

RESUME: Nous avons exécuté 15 études du flot cérébral régional (rCBF) chez 14 patients avec malformation artérioveineuses. Un seul patient fut étudié en proximité de l'hémorragie. Aucun patient ne fut opéré, quoique tous les patients aient des lésions bien démontrées angiogra. phiquement. Tous les patients chez qui une tomodensitométrie fut faite ont vu leur lésion illustrée par cette méthode. Le rCBF était augmenté dans l'hémisphère impliqué par ropport à l'autre et la différence était plus marquée lorsque les malformations étaient superficielles. L'incidence des régions à flots élevés dans l'hémisphère the involved hemisphere of patients with $A V M s$ compared to our normal control group and patients with subarachnoid hemorrhage ( $S A H$ ) from aneurysms. Flow rates within the involved hemisphere demonstrated abnormal distributions and greater variability than normals. Some peaks previously demonstrated in the intra-arterial flow studies are not apparent using the inhalation method. This noninvasive technique has a potential to provide additional useful information on the natural history of this disorder.

impliqué était plus élevée chez les patients avec malformations artérioveineuses par rapport au groupe de témoins normaux et aux patients avec anévrysmes. Les taux du flot dans l'hémisphère impliqué démontraient des distributions anormales et une variabilité plus grande que celle des normaux. Certains pics préalablement démontrés par les études de flot intraartériels ne sont plus apparents par la méthode d'inhalation. Cette méthode noninvasive a le potentiel d'ajouter plusieurs informations additionnelles sur l'histoire naturelle de ce désordre.

\section{INTRODUCTION}

There is little information on quantitative blood flow through arteriovenous malformations and the surrounding brain. Most studies have been done using the intracarotid injection techniques. We are reporting on a correlative angiographic, $C T$, and rCBF study on patients with AVMs. It is aimed at evaluating the inhalation method as a screening test for AVMs.

\section{METHOD}

Fourteen patients with angiographically demonstrated AVMs were studied. Twelve of these (Patients 1-12) underwent a single bilateral rCBF study each. No. 13 was measured only over the involved hemisphere. The last patient, No. 14, had suffered subarachnoid, intracerebral, and intraventricular hemorrhage and was studied twice, two weeks apart. The number of regions examined in each hemisphere varied from 7 to 16 .

Regional cerebral blood flow was measured using a 16-channel Xe-133 inhalation system (Medimatic,

Denmark). The unit comprises a Xe133 delivery system, a rebreathing loop, 17 scintillation detectors, and associated electronics. Sixteen of the detectors are $3 / 4^{\prime \prime} \times 3 / 4 " \mathrm{NaI}$ (T 1 ) crystals in 1" collimators; these monitor cerebral radioactivity. Expired air is monitored by a 1" crystal with air spiral. Clearance data from the detectors is collected on paper tape and analysed off-line by an HP 2100 computer. Analysis is based on the two-compartmental model of Obrist et al (1975); the non-compartmental slope index of Risberg et al (1975) is also calculated. Four parameters of interest are evaluated for each region studied; these are: From the Divisions of Neurosurgery and Biomedical
Engineering. Faculty of Medicine. University of Alberta, Edmonton

Reprint requests to: Dr. D. Menon, 10-102 Clinical Sciences Bldg., University of Alberta. Edmonton, Alberta, T6G 2G3, Canada. 
(1) Blood flow through grey matter $\mathrm{F}_{\mathrm{g}}(\mathrm{ml} / 100 \mathrm{~g} / \mathrm{min})$,

(2) Risberg's initial slope index ISI,

(3) Relative weight of grey matter $\mathrm{W}_{8}$, and

(4) Contribution of grey flow to total flow FF1 (\%)

Normal values for these parameters have been well documented by various groups (McHenry et al, 1978; Meyer et al, 1978; Blauenstein et al, 1977). The values obtained in this laboratory are tabulated in Table 1. A study of rCBF in aneurysms has previously been conducted (Weir et al, 1978); for purposes of comparison, some recent results obtained in patients with aneurysms will be included in the statistical analysis.

\section{RESULTS}

All grey flow values are given in $\mathrm{ml}$. of blood/gm of tissue/minute. Any $F_{g}$ greater than two standard deviations above the normal mean is defined as a fast flow. By this criterion, grey flows above $98 \mathrm{ml} / 100 \mathrm{~g} / \mathrm{min}$ are fast flows.

The patients were divided into two categories: those with deep AVMs, and those with superficial AVMs. AVMs which were deeper than $3 \mathrm{~cm}$ from the lateral skull are classified as deep; this is ascertained from anteroposterior angiograms. Patients $1-4$ and 14 had deep AVMs; 5-13 had superficial ones.

Figures 1-4 display rCBF patterns, angiograms, and $C T$ scans for four patients: two with deep AVMs (Patients 1 and 2) and two with superficial AVMs (patients 7 and 8 ). In the $\mathrm{rCBF}$

\section{TABLE 1}

Normal Values

\begin{tabular}{ll}
\hline $\mathrm{F}_{8}$ & $70 \pm 10.2$ \\
ISI & $60 \pm 8.3$ \\
$\mathrm{~W}_{8}$ & $0.48 \pm 0.06$ \\
FFI & $79 \% \pm 4 \%$ \\
\hline
\end{tabular}

$F_{1}:$ Grey flow in $\mathrm{ml} / 100 / \mathrm{min}$; ISI: Initial Slope Index;

W,: Relative weight of grey matter;

FFI: Contribution of grey flow to total flow.
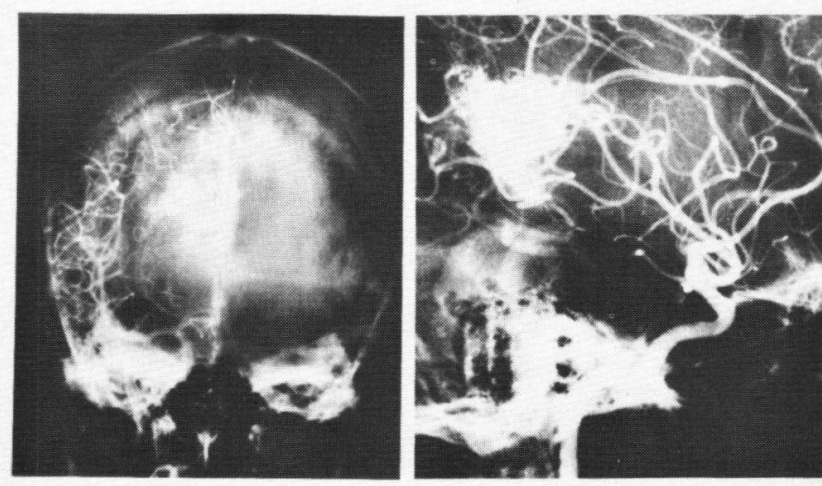

CASE NO.1 AGE: 25

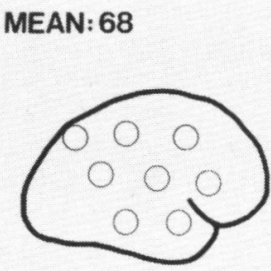

MEAN: 75
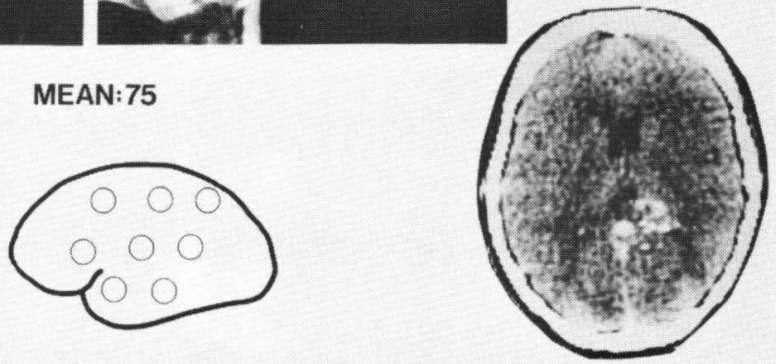

Figure 1 - Deep right parietal malformation. All flows are grey flows in $\mathrm{ml} / 100 \mathrm{gm} / \mathrm{min}$. Closed circles represent regions with high flow; normal flow regions are shown as open circles.
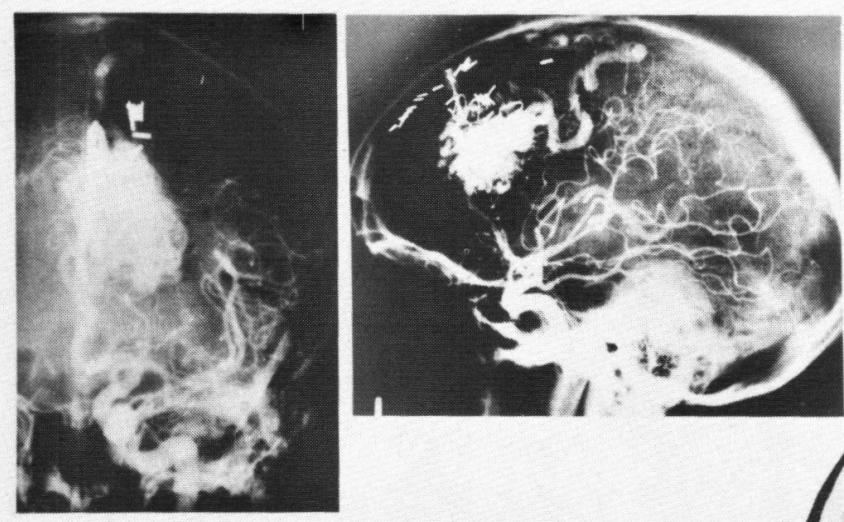

CASE NO. 2 AGE: 31
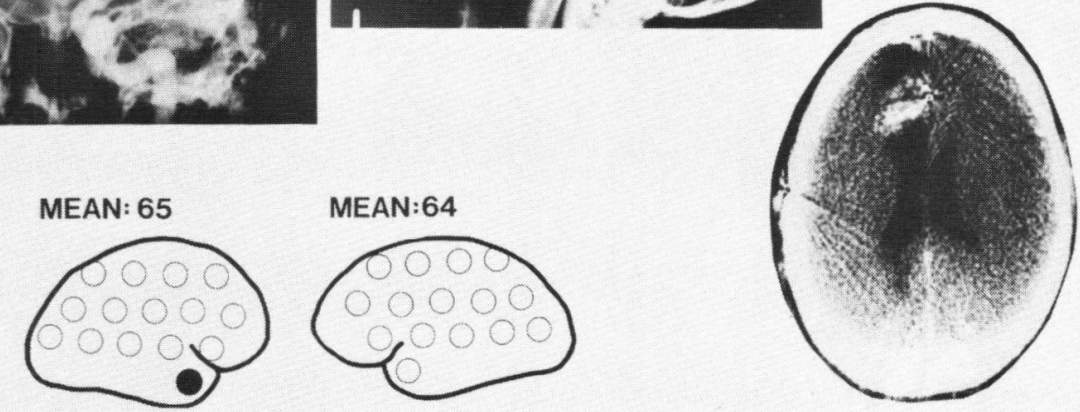

Figure 2 - Remotely operated deep left frontal malformation: a clot was evacuated five years prior to study. This was the only operated case. Closed circles represent regions with high flow; normal flow regions are shown as open circles. 

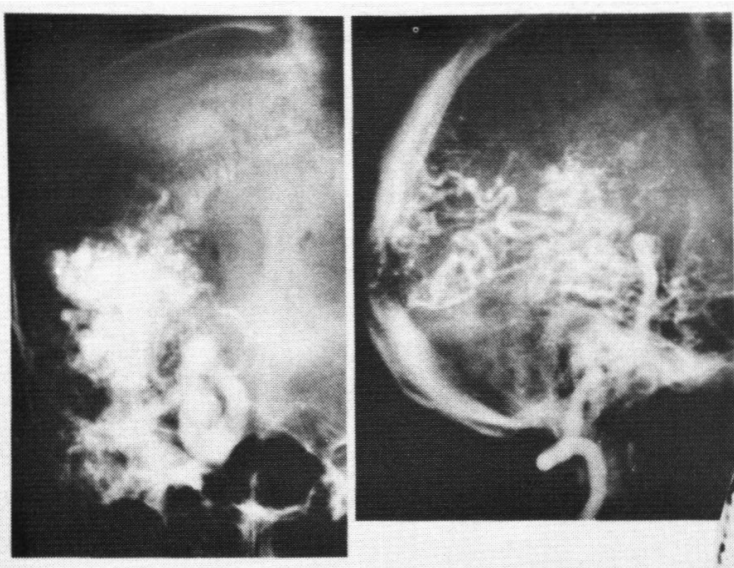

\section{CASE NO.7 \\ AGE : 31}
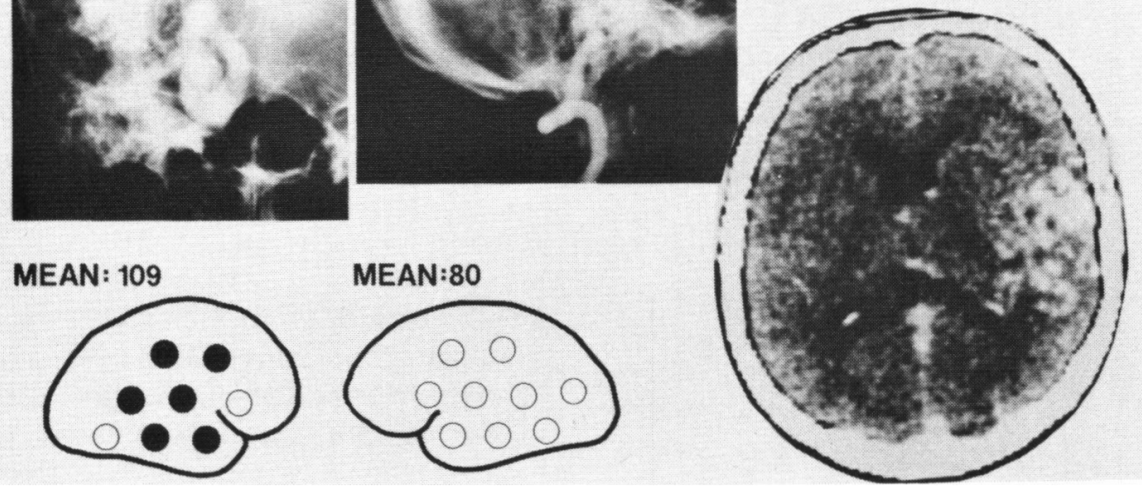

Figure 3 - Right temporal parietal occipital malformation, superficial and deep. Closed circles represent regions with high flow; normal flow regions are shown as open circles.
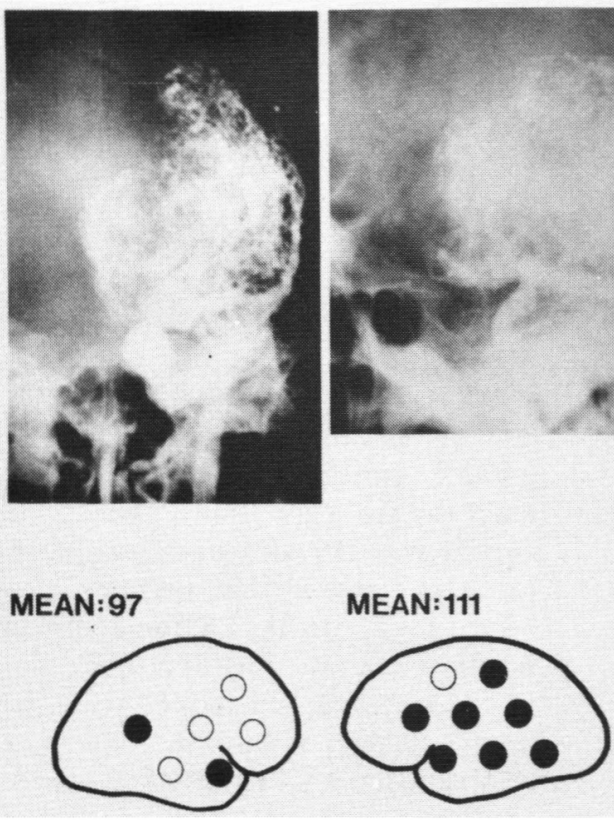

Figure 4 - Left parietal, superficial and deep malformation. Closed circles represent regions with high flow; normal flow regions are shown as open circles. diagrams, regions of high flow are denoted by solid circles and all other measured areas by open circles. Patient 14 had a hemorrhage and was studied twice; the results are contained in Figures 5a-5b. The patient was a 15 year old male. In the first study, flows were markedly depressed to roughly half of what would be expected; this correlated well with the presence of intraventricular hemorrhage as demonstrated by $\mathrm{CT}$. The second study, performed two weeks later, showed increased flow values. The CT scan at this time showed no intraventricular hemorrhage. The patient's neurological status had also improved.

The distribution of grey flows was measured in three groups - normals, $\mathrm{SAH}$, and AVMs, and is plotted in Figure 6. Whereas low flows are more prevalent in patients with aneurysms, higher flows are observed in AVMs.

Table 2 compares hemisphere flows for patients 1-12. It is obvious that hemisphere differences are more apparent in the group of superficial AVMs. In Table 3 , a comparison is made between the various groups of the fraction of flows measured that are greater than $98 \mathrm{ml} / 100 \mathrm{~g} / \mathrm{min}$.

Distribution of flow rates within each hemisphere is measured by the coefficient of variation C.V. (C.V. = standard deviation/mean in \%). The larger the C.V., the wider the range of rCBF values present. This in turn implies a more abnormal distribution. Table 4 shows the different scatter in rCBF determined for the various groups.

\section{DISCUSSION}

Various techniques have been employed over the past 25 years for the detection and study of intracranial arteriovenous malformations. It is generally accepted that the most reliable of these is cerebral angiography. Although necessary as a pre-operative procedure, angiography is unsuitable as a screening test, primarily because it is invasive. Static and dynamic scintigraphy have also been employed with varying results depending upon the location, size, etc. of the lesion (Waltimo et al, 1973; Gates et al, 1978). Recently, computer tomography has become more widely 
TABLE 2

Interhemispheric grey flow differences

\begin{tabular}{lcc}
\hline & Involved Hemisphere & Non-involved Hemisphere \\
\hline Deep AVMs* & $90 \pm 19.2$ & $81 \pm 13.0^{* *}$ \\
Deep AVMs* & $76 \pm 13.1$ & $81 \pm 13.1^{* *}$ \\
Superficial AVMs & $98 \pm 18.3$ & $82 \pm 13.9^{* * *}$ \\
\hline
\end{tabular}

- Arteriovenous Malformations

** No statistically significant difference

*** Statistically significant difference at $p<.05$ level

TABLE 3

Prevalence of High Flow's

\begin{tabular}{lcc}
\hline & Involved Hemisphere & Non-Involved Hemisphere \\
\hline All AVMs* & $32 \%$ & $14 \%$ \\
Deep AVMs* & $15 \%$ & $19 \%$ \\
Superficial AVMs* & $42 \%$ & $12 \%$ \\
Normals & & $7 \%$ \\
SAH** & $5 \%$ & \\
\hline
\end{tabular}

- Arteriovenous Malformations

* Subarachnoid Hemorrhage Patients

TABLE 4

Coefficient of Variation of Grey Flow

\begin{tabular}{lcc}
\hline & Involved Hemisphere & Non-involved Hemisphere \\
\hline All AVMs* & $22.7 \%$ & $17.5 \%$ \\
Deep AVMs* & $23.0 \%$ & $22.5 \%$ \\
Superficial AVMs* & $22.5 \%$ & $15.0 \%$ \\
Normals & & $15.2 \%$ \\
SAH $^{* *}$ & & $24.2 \%$ \\
\hline
\end{tabular}

- Arteriovenous Malformations

* Subarachnoid Hemorrhage Patients used (Pressman et al, 1975; Terbrugge et $\mathrm{al}, 1977)$. It is claimed that CT is as effective as angiography in detecting AVMs. In addition to the procedure being simpler, complications such as intraventricular hemorrhage (IVH) and hydrocephalus may be visualized on a CT scan.

Apart from these more standard tests, a small number of studies have been conducted to determine cerebral perfusion patterns. The majority of these employed the Xenon 133 (Xel33) intracarotid injection technique (Lassen \& Ingvar, 1972) to obtain regional cerebral blood flow (rCBF) values (Haggendal et al, 1965; Mosmans, 1974). These studies revealed the presence of super-high flows in AVMs, as evidenced by the shunt-peaks seen in the cerebral clearance curves. In patients studied post-operatively, these peaks were flattened and overall flow over the AVM dropped (Oeconomos et al, 1969; Kawamura et al, 1977).

The basic difficulty with the intracarotid technique lies in the fact that arterial puncture is necessary; this necessity limits its applicability to longitudinal studies of AVMs. However, with the development of a noninvasive rCBF procedure (Obrist et al, 1975), it has become possible to measure rCBF much more safely and readily. It has the added advantage that simultaneous bilateral measurement is possible. There is little mention in the literature of the application of this method to arteriovenous malformations (Deshmukh \& Meyer, 1978; Meyer, 1978).

The intra-arterial method demonstrates shunt peaks in which count rates drop to $1 / 6$ of their peak count in about 5 seconds. We did not see these when using the inhalation method. This is because the radioisotope is inhaled continuously and does not enter the brain as a bolus. The washout curves will be consistently smoother using the inhalation method. However, high flows characteristic of AVMs were noted as expected.

The very marked reduction in flow found in the young male with an intraventricular hemorrhage was in agreement with our earlier work on subarachnoid hemorrhage from ruptured aneurysms in which intraventricular hemorrhage was shown to be 
the feature most closely associated with depressed rCBF. (Weir et al, 1978).

The use of a 16 channel machine will not provide anatomical detail of even superficial AVMs, but does provide quantitative information. In longitudinal studies of the same patient this should provide useful information on the development of ischemic change in brain surrounding an AVM or in documenting global ischemia in the event of complications such as hemorrhage. In conjunction with augmented CT scans these two non-invasive methods approach a high level of diagnostic accuracy, and in patients in whom surgery is not contemplated the diagnosis of an AVM can probably be safely made without resorting to angiography with the attendant risks.

\section{ACKNOWLEDGEMENT}

We appreciate the support of the Medical Research Foundation (Alberta) which made this study possible.

\section{REFERENCES}

BLAUENSTEIN, O.W., HALSEY, J.H and WILSON, E.M. et al (1977). Xenon Inhalation Method, analysis of reproducibility: some of its physiological implications. Stroke 8:92-102.

DESHMUKH, V.D. and MEYER, J.S. (1978). "Non invasive Measurement of Regional Cerebral Blood Flow in Man". Spectrum Publications, New York pp. 168-173.

GATES, G.F., FISHMAN, L.S. and SEGALL, H.D. (1978). Scintigraphic Detection of Congenital Intracranial Vascular Malformations. J. Nucl. Med. 19:235-244.

HAGGENDAL, E., INGVAR, D.H. and LASSEN, N.A. et al (1965). Pre- and postoperative measurements of regional cerebral blood flow in three cases of intracranial arteriovenous aneurysms. J. Neurosurg. 22:1-6.

KAWAMURA, Y., KURIMOTO, T., and SOMEDA, K. et al (1977). Regional Cerebral blood flow study with Autofluoroscopic system-70 and its application to preand post-operative evaluation of arteriovenous malformation patients. Proc. 24th Annual Meeting of the Society of Nuclear Medicine, Chicago, June 1977.

LASSEN, N.A. and INGVAR, D.H. (1972). Radioisotopic assessment of regional cerebral blood flow. Prog. Nucl. Med. 1:376-409.

McHENRY, L.C., MERORY, J. and BASS, E. et al (1978). Xenon-133 inhalation method for regional cerebral blood flow measurements: Normal values and test-retest results. Stroke 9:396-399.

MEYER, J.S. (1978). Personal Communication.
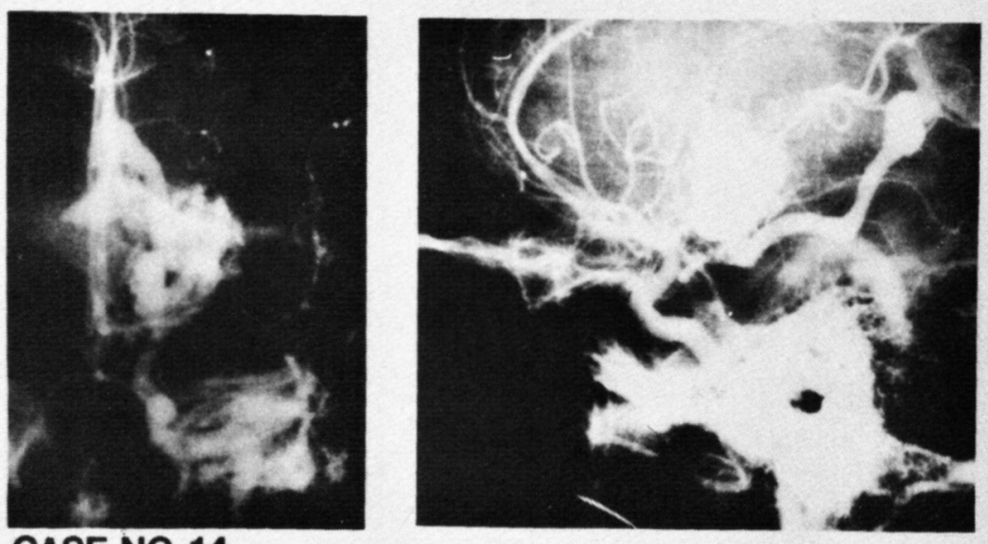

CASE NO. 14

AGE:15

Figure $5 a$ - AP and lateral carotid angiograms showing deep left frontoparietal malformation.

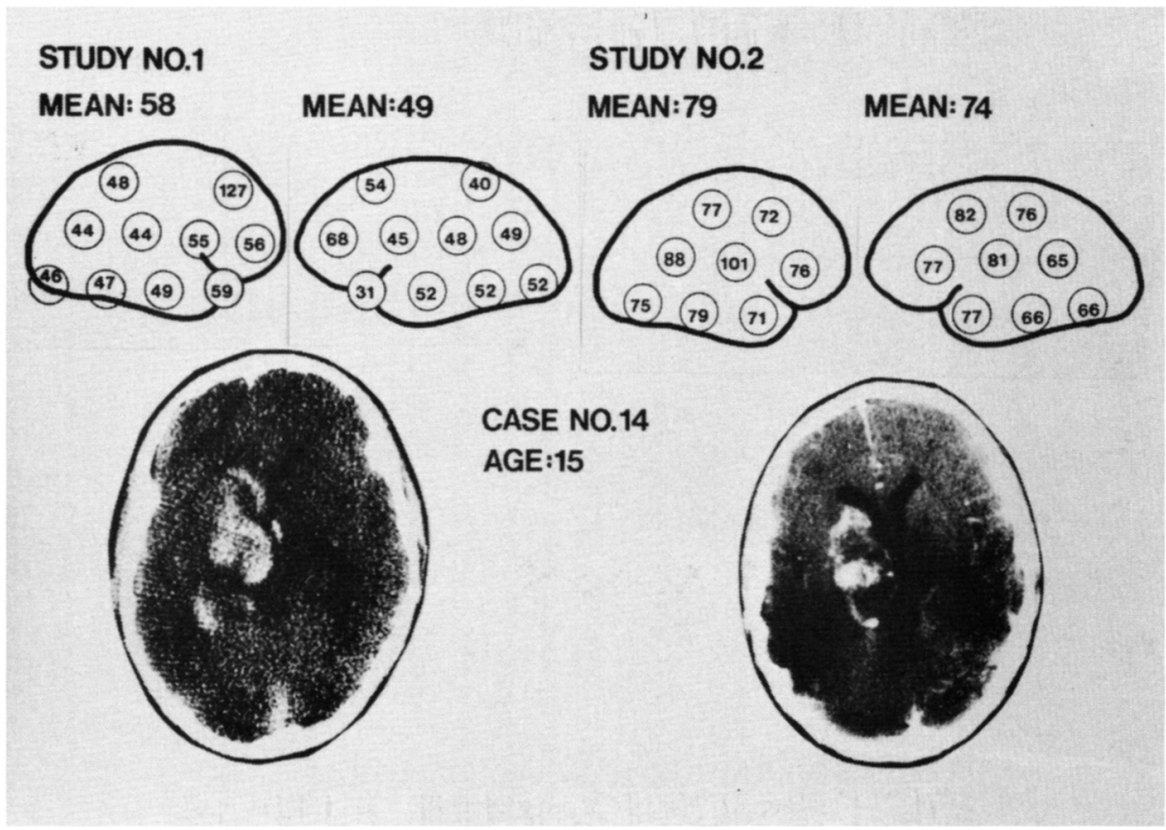

Figure $5 b$ - Actual grey flows and CT scans on same case. The numbers within the circles are grey flows in $\mathrm{ml} / 100 \mathrm{~g} / \mathrm{min}$. Study 1 was carried out 6 days following hemorrhage when patient was severely obtunded, aphasic and hemiplegic. Study 2 was carried out two weeks later when patient was alert and only minimally dysphasic and hemiparetic. Note clearing of intraventricular clot.

MEYER, J.S., ISHIHARA, N. and DESHMUKH, V.D. et al (1978). Improved method for non-invasive measurement of regional cerebral blood flow by Xenon-133 inhalation. Part I. Stroke 9:195-204.

MOSMANS, P.C. (1974), "Regional Cerebral
Blood Flow in Neurological Patients" Van Gorcum, Netherlands pp. 71-74.

OBRIST, W.D., THOMPSON, H.K. and WANG, H.S. et al (1975). Regional Cerebral Blood Flow estimated by 133 Xenon inhalation. Stroke 6:245-255. 


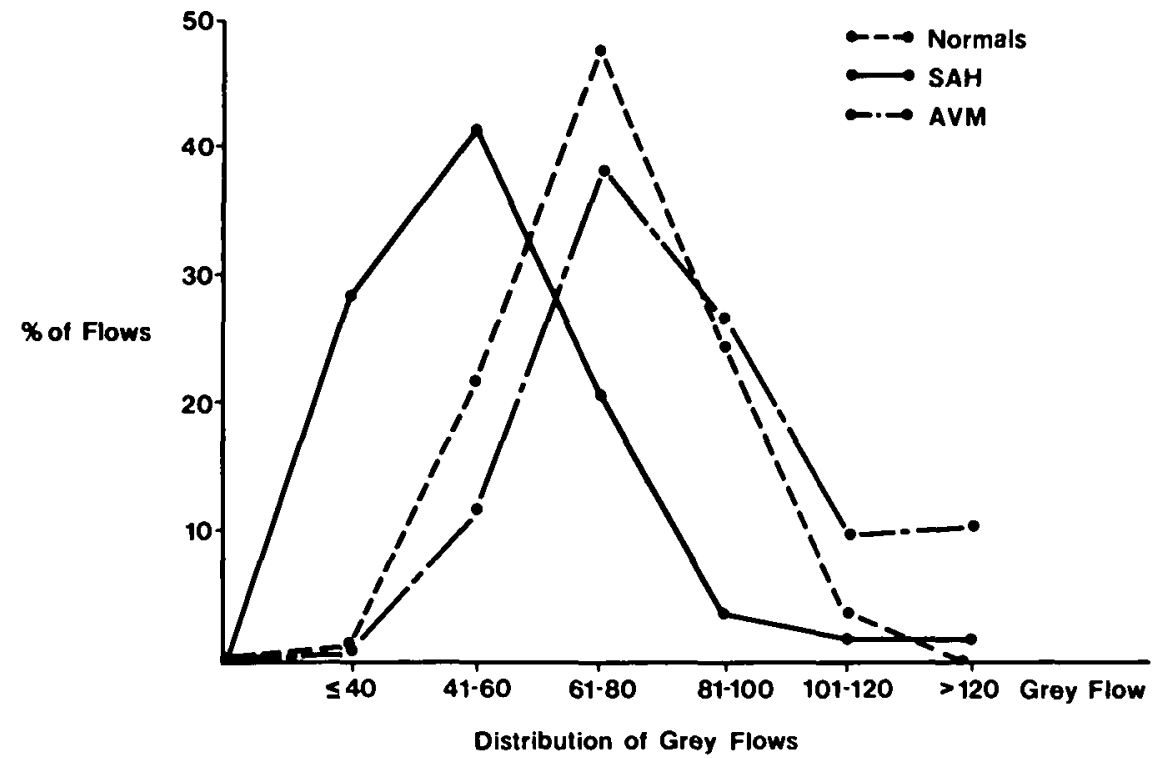

Figure 6 - Comparison of distribution of grey flows in normals, subarachnoid hemorrhage from aneurysms, and arteriovenous malformations.
OECONOMOS, D., KOSMAOGLOU, D. and PROSSALENTIS, A. (1969). rCBF studies in patients with arteriovenous malformations of the brain in "Cerebral Blood Flow Clinical and Experimental Results". SpringerVerlag, Berlin. pp. 146-148.

PRESSMAN, B.D., KIRKWOOD, J.R. and DAVIS, D.O. (1975). Computerized Transverse Tomography of Vascular Lesions of the Brain. Part I: Arteriovenous Malformations. Am. J. Roentgenol. 124: 208-214.

RISBERG, J., ALI Z. and WILSON E.M. et al (1975). Regional cerebral blood flow by 133 Xenon inhalation. Stroke 6: 142-148.

TERBRUGGE K., SCOTTI G. and ETHIER R. et al (1977). Computed Tomography in intracranial arteriovenous malformations. Radiology 122: 703-705.

WEIR B., MENON D. and OVERTON T. (1978). Regional Cerebral Blood Flow in patients with aneurysms: Estimation by Xenon 133 Inhalation. Can. J. Neurol. Sci. 5: 301-305. 